\title{
When to Start Antiretroviral Therapy
}

\author{
Vivek Jain • Steven G. Deeks
}

Published online: 11 April 2010

(C) The Author(s) 2010. This article is published with open access at Springerlink.com

\begin{abstract}
The question of when to start combination antiretroviral therapy for treatment-naïve patients has always been controversial. This is particularly true in the current era, with major guidelines recommending very different treatment strategies. Despite a lack of clarity regarding the optimal time to begin therapy, there has been a recent shift toward earlier initiation. This more aggressive approach is driven by several observations. First, effective viral suppression with therapy can prevent non-AIDSrelated morbidity and mortality. Second, therapy can prevent irreversible harm to the human immune system. Third, therapy may prevent transmission of HIV to others, and thus have a potential public health benefit. For patients who are motivated and willing to initiate early treatment, the collective benefits of early therapy may outweigh the well-documented risks of antiretroviral medications.
\end{abstract}

Keywords HIV A Antiretroviral therapy

Early treatment " "When to start". Clinical trials .

Observational studies · Non-AIDS conditions .

"Test and treat" - Systemic inflammation · T cell activation

\section{Introduction}

Since the introduction of zidovudine in 1987, the question of when antiretroviral therapy for HIV should be initiated has been often debated but never fully elucidated. Due to the absence of a definitive and timely study, the decision of "when to start" has often been based on expert interpreta-

V. Jain $(\bowtie) \cdot$ S. G. Deeks

HIV/AIDS Division, San Francisco General Hospital,

University of California, San Francisco,

Box 0874, San Francisco, CA 94110, USA

e-mail: vivek.jain@ucsf.edu tion of observational cohort data, HIV pathogenesis studies, and the safety and efficacy of available therapeutic options [1]. This review summarizes some of this historical context, and then discusses the rationale for the current shift in recommendations away from a conservative approach based on delaying antiretroviral initiation as long as possible to a much more aggressive approach in which very early therapy is recommended or considered for nearly all patients. Critical studies still in progress will also be reviewed, as will research on the possible public health benefits of an aggressive "test and treat" approach to therapy.

\section{The Historical Perspective}

After the introduction of zidovudine monotherapy as a potentially effective agent, the question of "when to start" this poorly tolerated drug became a dominant clinical question. Several early studies attempted to address this question. AIDS Clinical Trials Group 019 suggested that over the short term, the use of zidovudine monotherapy in asymptomatic patients was associated with measurable clinical benefit [2], an observation that led to a general recommendation that this drug be used early in the disease process. This benefit, however, did not prove to be durable [3], and a subsequent randomized trial of very early zidovudine (CD4>500 cells $/ \mu \mathrm{L})$ compared to deferred therapy $(\mathrm{CD} 4<500$ cells $/ \mu \mathrm{L})$ revealed no benefit for the earlier use of this drug [4]. Therapeutic pessimism became a dominant theme throughout the "when to start" debate.

This pessimism lifted with the advent of combination antiretroviral therapy in 1996. The dramatic effects of threedrug therapy in clinical trials, coupled with emerging insights regarding viral dynamics and HIV evolution, renewed interest in the concept that therapy should be initiated very early. Much 
of this philosophy was summarized by the "hit HIV, early and hard" paradigm [5] and was reflected in the US Department of Health and Human Services (DHHS) HIV treatment guidelines between 1998 and 2000, which recommended that most patients be offered therapy, including those with asymptomatic disease and a CD4 cell count above 500 cells/ $\mu \mathrm{L}[6,7]$.

After this period of expanding antiretroviral drug use, concerns began to mount about the pill burden and toxicities of antiretroviral regimens, and about the high risk of developing drug-resistant HIV. This new awareness of the limitations of therapy forced clinicians and expert panels to question whether potential benefits of therapy outweighed the potential risks at higher CD4 cell counts. This, in turn, led to a sense among patients and clinicians that medications should be delayed as long as possible. Several cohort studies during this era indicated that a higher pre-treatment CD4 was a strong predictor of good outcomes during therapy, with consistent and clear benefits occurring if therapy was initiated before the CD4 declined to below 200 cells $/ \mu \mathrm{L}$, but additional benefit was also apparent when therapy was initiated at a CD4 of 200 to 350 cells/ $\mu \mathrm{L}$ [8-10]. The 2001 version of the DHHS guidelines was accordingly modified such that therapy was strongly recommended for those with a CD4 below 200 cells/ $\mu \mathrm{L}$, and generally recommended for those with a CD4 count of 200 to 350 cells $/ \mu \mathrm{L}$, although with certain caveats. Therapy in patients with higher CD4 cell counts was generally not recommended [11].

In recent years, the rationale for delaying antiretroviral therapy has become less compelling. Co-formulation of antiretroviral drugs has greatly improved, lowering the average pill burden for patients, and allowing for an antiretroviral regimen consisting of a single daily tablet (tenofovir/emtricitabine/efavirenz). Side effect and toxicity profiles have also improved. Several new potent and welltolerated options are now available, making it more likely that all patients can be offered an effective regimen with minimal side effects (and also making it more likely that second-line and third-line options will be available if the primary regimen fails to durably suppress viral replication). Finally, and perhaps most importantly, evidence from a randomized controlled trial (the Strategies for Management of Antiretroviral Therapy, or SMART study) raised the concern that early untreated HIV infection might be associated with an increased risk of a number of important non-AIDS conditions, including cardiovascular, liver, and kidney dis-

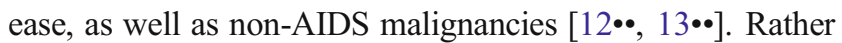
than simply preventing classical AIDS-related opportunistic conditions and deaths, many clinicians have come to believe that antiretroviral therapy is also key to maintaining general health. Several recent cohort studies (described below) have provided some support for this far more aggressive approach to therapy.

\section{Observational Studies}

Observational cohort studies have played a critical role in the ongoing debate about the optimal time for the initiation of antiretroviral therapy. Findings from cohort studies played a particularly important role in showing mortality benefits for antiretroviral initiation below a CD4 count of 350 cells $/ \mu \mathrm{L}[8,10,14,15]$. The most clinically relevant question now is to determine whether antiretroviral therapy should be deferred until the CD4 count reaches 350 cells/ $\mu \mathrm{L}$, or whether therapy should be started earlier. Here, again, cohort studies continue to yield valuable although nondefinitive and often inconsistent insights.

A key study addressing the question of starting therapy at a higher CD4 threshold was a 2009 analysis of patients in NA-ACCORD, a large "cohort of cohorts" that merged clinical data from 22 observational studies in the United States and Canada. Kitahata et al. [16••] identified treatmentnaive patients with CD4 counts in one of two strata: 350 to 500 cells $/ \mu \mathrm{L}$ and more than 500 cells $/ \mu \mathrm{L}$. Patients who entered the cohort with a CD4 cell count in these ranges and who started therapy within the next 6 months were compared to patients who did not initiate therapy and allowed their CD4 cell counts to fall to below a predefined threshold. Using inverse probability of treatment weighting methodology, the authors performed two complementary analyses. The first analysis concluded that deferral of therapy until a CD4 cell count below 350 cells $/ \mu \mathrm{L}$ was associated with a $69 \%$ increase in the relative risk of mortality as compared to initiation of therapy between 350 and 500 cells/ $\mu \mathrm{L}$ (adjusted risk ratio: $1.69 ; 95 \% \mathrm{CI}=1.26-2.26)$ [16••]. These data were generally consistent with other cohorts and post hoc analysis of the SMART study (described below), and hence were not particularly controversial. The second analysis showed that deferral of therapy until the CD4 count was below 500 cells/ $\mu \mathrm{L}$, as compared to initiation at a CD4 greater than 500 cells/ $\mu \mathrm{L}$, was associated with a $94 \%$ increase in the relative risk for death (adjusted risk ratio: $1.94 ; 95 \% \mathrm{CI}=1.37-2.79$ ). It is important to stress that although the risk appeared to be large, the number of events was small (even in the deferral group), making the absolute level of clinical benefit associated with early therapy unclear. Despite these concerns, these data provided some evidence that very early therapy may be beneficial, and provided clear evidence that it was at least not harmful.

The NA-ACCORD study's striking findings generated some methodological criticisms, most of which were centered around the possibility that the decision to initiate therapy early in clinical practice was confounded by factors that also influence mortality (the "healthy lifestyle bias") [17]. The authors addressed this possibility by simulating how their results would change if a confounder with a very strong association with both the exposure and outcome of 
interest was present. Notably, their results were only slightly attenuated, and remained significantly in favor of earlier antiretroviral therapy. Additional concerns about this analysis included its complex sample selection scheme, which excluded a large number of NA-ACCORD patients. This may have rendered the study less generalizable to all antiretroviral-naive patients, as it appeared to handle longterm non-progressors (patients for whom the benefits of early therapy are far less certain) differently in the two comparison groups [18]. The results, however, did not change appreciably when this censoring was handled nondifferentially, further supporting the central findings.

Another very influential 2009 cohort study, performed by the Antiretroviral Therapy Cohort Collaboration (ART-CC), examined 24,444 patients from 15 cohorts (most in Europe) who initiated antiretroviral therapy at CD4 counts less than 550 cells $/ \mu \mathrm{L}$ and compared mortality rates for different CD4 counts at treatment initiation [19••]. One methodologic concern with the ART-CC data was that it only included data from the time antiretroviral therapy was initiated, and thus did not have data regarding morbidity and mortality during the pre-therapy untreated phase. This resulted in a potential lead-time bias in which untreated patients who developed an AIDS-defining event or who died before the initiation of therapy could not be included in the analysis. To address this concern [20], the authors analyzed event rates on 21,247 patients who received care between 1989 and 1995, when combination antiretroviral therapy was not available. They then used multiple imputation to allow these events to represent those that might have occurred in the patients of interest (individuals who started combination antiretroviral drugs from 1996 onward), and allowed these events to contribute to the calculated mortality rates. The final analysis found that deferral of antiretroviral therapy until a CD4 count of 251 to 350 cells $/ \mu \mathrm{L}$, compared to initiating therapy when at a CD4 count of 351 to 450 cells $/ \mu \mathrm{L}$, was associated with an adjusted $28 \%$ increase in the rate of death or AIDS (adjusted hazard ratio for AIDS or death: $1.28 ; 95 \% \mathrm{CI}=1.04-1.57$ ) [19••]. The harm associated with deferring therapy was less clear at CD4 counts more than 350 cells $/ \mu \mathrm{L}$. In contrast with the NA-ACCORD analysis, the ART-CC analysis found no clear risk in deferring therapy in patients with CD4 counts in the higher ranges. For example, deferral of therapy until a CD4 count of 351 to 450 cells $/ \mu \mathrm{L}$ was not associated with harm compared to initiation of therapy at a CD4 count of 451 to 550 cells $/ \mu \mathrm{L}$ (adjusted hazard ratio for AIDS or death: $0.99 ; 95 \% \mathrm{CI}=0.76-1.29$ ). Similarly, deferral of therapy until a CD4 count of 301 to 400 cells $/ \mu \mathrm{L}$, compared to initiation of therapy at a CD4 count of 401 to 500 cells $/ \mu \mathrm{L}$, was also not associated with harm (adjusted hazard ratio= $1.09 ; 95 \% \mathrm{CI}=0.85-1.38$ ). The authors conclude that a CD4 threshold of 350 cells $/ \mu \mathrm{L}$ may be the optimal (or at least minimal) threshold for initiating antiretroviral therapy.
As was the case with the NA-ACCORD study, this study generated several methodologic criticisms. Chief among these was that the imputed event and death rates from the era before combination therapy became widely available may have been different than in the modern treatment era [21]. The authors acknowledged that these event rates were potentially misrepresentative, but additional analyses show that this was unlikely to have altered the fundamental results $[19 \bullet \bullet]$. Perhaps more importantly, non-AIDS-related events, such as cardiovascular disease, renal disease, and liver failure, were not included among the outcomes analyzed. Given that the benefits of earlier antiretroviral initiation may specifically involve these diseases, their exclusion may at least partially explain why the study did not show a clinical benefit when antiretroviral therapy was started at CD4 counts above 350 cells $/ \mu \mathrm{L}$.

\section{Randomized Controlled Clinical Trials}

Most of the current recommendations on when to start antiretroviral therapy are based primarily on observational studies and HIV pathogenesis. Making clinical recommendations based on such types of studies is problematic, a fact well illustrated by the confusion regarding the use of estrogen in postmenopausal women. Randomized clinical trials are the gold standard methodology for generating evidence to guide therapeutic strategies, and several have provided clear support for the use of early therapy in patients with lower CD4 cell counts $[22,23]$ and in HIVinfected infants [24]. These studies, however, inform different clinical questions than the current debate, which focuses on asymptomatic adults with CD4 counts above 350 cells $/ \mu \mathrm{L}$.

Although not a classic "when to start" randomized clinical trial, the SMART study has proven to be the most important study in the modern era in terms of its impact on when and how therapy is used. This study, which began in 2002 and was reported in 2006 [12••], randomized more than 5,000 patients to a continuous "viral suppression" arm, in which antiretroviral therapy was started and continued without regard to the CD4 count, versus a "drug conservation" arm, in which therapy was initiated if the CD4 count declined below 250 cells $/ \mu \mathrm{L}$ but halted if the CD4 count rose above 350 cells $/ \mu \mathrm{L}$. The hazard ratio for opportunistic disease or all-cause death for patients in the treatment interruption arm was $2.6(95 \% \mathrm{CI}=1.9-3.7)[12 \bullet \cdot]$. When investigators examined causes of death in the trial, they found many patients had suffered from non-AIDS-related morbidity and mortality, including cardiovascular, hepatic, and renal disease. Indeed, the hazard ratio for these nonAIDS-defining illnesses was $1.8(95 \% \mathrm{CI}=1.2-2.9)$, showing that patients who discontinued antiretroviral therapy 
when their CD4 rose above 350 cells/ $\mu \mathrm{L}$ suffered a marked excess morbidity and mortality, chiefly manifest as cardiovascular, hepatic, and renal disease (though many suffered traditional AIDS-related opportunistic diseases and death).

A subset of the SMART study reported data on 477 participants ( $9 \%$ of the original randomized trial) who at study entry were either antiretroviral therapy naïve or who had been untreated for at least 6 months [13••]. In essence, this substudy functioned like a randomized controlled trial of antiretroviral initiation at $\mathrm{CD} 4$ counts more than 350 cells $/ \mu \mathrm{L}$ compared to deferral of therapy until CD4 counts were below 250 cells $/ \mu \mathrm{L}$. Subjects in the deferral arm fared poorly: the hazard ratio for opportunistic disease or all-cause death was 3.47 (95\% CI=1.26-9.56). Moreover, the hazard ratio for serious non-AIDS events (defined as cardiovascular, hepatic, and renal disease, along with non-AIDS-related malignancies) was 7.02 (95\% CI=1.57-31.38). Comparable trends were observed when the analysis was limited to those who were treatment naïve at study entry.

In the developing world, clinical practice has been most strongly influenced by the World Health Organization (WHO) treatment guidelines, which until recently recommended initiating antiretroviral therapy at a target CD4 threshold of 200 cells $/ \mu \mathrm{L}$ [25]. In 2009, the CIPRA-HT001 study was the first to investigate potential benefits of a higher CD4 threshold for therapy in a developing world setting where routine clinical practice is to initiate therapy at a CD4 count of 200 cells $/ \mu \mathrm{L}$. Beginning in 2005, investigators randomized 816 patients in Haiti with CD4 counts of 200 to 350 cells $/ \mu \mathrm{L}$ to immediate antiretroviral therapy versus deferral of therapy until either a CD4 less than 200 cells $/ \mu \mathrm{L}$ or an AIDS-defining diagnosis [26••]. In May 2009, a data safety monitoring board halted the trial because the immediate treatment arm had markedly lower mortality than the deferred treatment arm (six deaths vs 23 deaths, respectively). In addition, the study also showed that incident tuberculosis was markedly reduced in the immediate treatment arm (18 cases vs 36 cases). This study played a central role in the November 2009 update to the WHO treatment guidelines, which now recommend antiretroviral therapy for all persons with CD4 counts less than 350 cells $/ \mu \mathrm{L}[27 \bullet \bullet]$.

\section{The Role of Antiretroviral Drugs in Reducing Non-AIDS-Related Morbidity and Mortality}

Despite tremendous reductions in AIDS-related deaths and opportunistic disease in the combination antiretroviral era, HIV-infected persons still suffer excess mortality compared to the general population [28••, 29-32]. Many studies have shown that much of this excess mortality is attributable to cardiovascular disease, non-AIDS-associated cancers, liver disease, and kidney disease [30, 33-35]. The increased risk of these non-AIDS events is likely multifactorial in nature, and includes an excess of traditional risk factors in HIV-positive compared to HIV-negative persons, direct antiretroviral treatment toxicities, and HIV-associated immunologic abnormalities that persist during treatment [33, 34]. Regardless of the mechanisms, it is reasonable to assume that HIVassociated morbidity and mortality in the future will likely increasingly focus on the prevention and management of the non-AIDS conditions.

The treatment-associated reductions in non-AIDSrelated conditions drove, in large part, the mortality benefits observed in patients with CD4 counts more than 350 cells $/ \mu \mathrm{L}$ in the SMART study [12••], as well as in patients with CD4 more than 500 cells $/ \mu \mathrm{L}$ in the NAACCORD analysis [16*0]. The discovery that treatment can prevent these non-AIDS events is also supported by robust analyses linking the on-therapy (or proximal) CD4 cell count with the short-term risk of developing a nonAIDS event [34, 36-38]. Since lower on-therapy CD4 cell counts predict an increased risk of non-AIDS events, it is reasonable to assume that any intervention that prevents the loss of immune function may be associated with clinical benefit. Given the current inability to restore immune function with immune-based therapeutics [39], and given that HIV-associated immunodeficiency may be irreversible in some patients $[40,41]$, the most effective approach to preventing disease in HIV-positive persons may be to initiate antiretroviral therapy before the onset of any measurable immunodeficiency. Theoretically, this would be as early as possible, perhaps even during primary infection. It should be emphasized, however, that the detrimental effects associated with lower on-therapy CD4+ T-cell counts are only apparent in patients with CD4 cell counts well below 500 cells $/ \mu \mathrm{L}$.

\section{HIV Pathogenesis and the Role of Inflammation in Disease Outcomes}

It is now well accepted that HIV-mediated increases in T-cell activation have a central role in the pathogenesis of untreated HIV infection [42, 43]. T-cell activation also predicts a higher risk of AIDS and death in late-stage disease [44]. Despite these findings, the role of systemic inflammation in untreated disease has previously received limited attention among clinicians, who were understandably more focused on achieving control of HIV replication. Now that we are in an era in which nearly all motivated patients with access to care can achieve durable and perhaps indefinite control of HIV replication, more attention is turning to the potential harms, both temporary and permanent, of HIV-associated inflammatory states. 
Emerging data suggest that systemic inflammation may play a central role in the pathogenesis of a number of nonAIDS-related conditions not been previously linked to immunodeficiency $[45 \bullet \bullet, 46]$. Among the participants in the SMART study (which compared continuous therapy vs intermittent therapy), periods of untreated HIV infection were associated with higher levels of biomarkers of systemic inflammation and hypercoagulability [45*0]. The levels of these biomarkers were associated with the overall risk of mortality (importantly, this increased risk was independent of both CD4 cell count and plasma HIV-1 RNA levels). A number of other studies have implicated HIV-associated inflammation with premature onset of cardiovascular disease, kidney dysfunction, liver failure, neurocognitive decline, and osteopenia/osteoporosis [34].

Combination antiretroviral therapy lowers HIV-associated immune activation over short time periods, but often does not lower it to the level seen in HIV-negative persons [47]. That this persistent inflammation is not abrogated by therapy is particularly evident among patients who do not initiate therapy until more advanced stages of HIV (CD4 counts $<$ $350-500$ cells $/ \mu \mathrm{L}$ ) [48]. These data collectively suggest but do not definitively prove that persistent inflammation during therapy is harmful, and that one way to prevent this process may be to initiate therapy earlier in the disease process, perhaps even before measurable immunodeficiency is readily apparent. It is hoped that ongoing randomized studies of "when to start" may provide a platform for exploring the role of early therapy in preventing irreversible immunologic harm.

\section{Universal HIV Testing and Immediate Treatment: The "Test and Treat" Strategy}

Among untreated persons, the plasma HIV RNA level is a strong and consistent predictor of a person's ability to transmit HIV to a partner. Although not formally proven, it is highly likely that effective antiretroviral therapy dramatically reduces the ability of an infected person to transmit HIV to others. These observations and theoretical considerations have led to an intriguing question: why not test as many people as possible and then offer lifelong treatment to those who are HIV positive? This so-called "test and treat" approach has been advocated by others $[49,50]$ and has been recently proposed in a widely publicized mathematical model. This study, modeled on South African data and reflective of a high-prevalence setting, showed that universal annual voluntary HIV testing and immediate post-diagnosis initiation of antiretroviral therapy in all persons older than 15 years could reduce the transmission of HIV and begin to drive the HIV epidemic toward extinction [51••]. Furthermore, the model indicates that an initial increase in cost (due to an increasing number of patients requiring therapy) would be followed by a subsequent further decrease in cost (due to decreased incident cases) as more infections are prevented. These potential public health considerations are increasingly being used to support early therapy and were cited as important by the DHHS Panel when their recommendations shifted dramatically to earlier therapy (see below).

\section{Major Revisions to Clinical Practice Guidelines in 2008-2009}

In 2008/09, several HIV treatment guidelines were revised in favor of earlier initiation of antiretroviral therapy at higher CD4 cell counts (Table 1). In December 2009, the DHHS recommended therapy for all patients with CD4 cell counts in the 350 to 500 cells $/ \mu \mathrm{L}$ range, although the group was divided as to whether this was a "strong" or "moderate" recommendation. The DHHS panel was also generally supportive of therapy in patients with $\mathrm{CD} 4$ cell counts more than 500 cells $/ \mu \mathrm{L}$, with $50 \%$ recommending therapy and $50 \%$ arguing that therapy should be optional (it is of interest that the active deferral of therapy was not recommended) [52••]. The European AIDS Clinical Society in November 2009 recommended treatment at a CD4 less than 350 cells/uL, and consideration of treatment at CD4 counts more than 350 cells $/ \mu \mathrm{L}$ if one or more comorbidity is present [53]. The International AIDS Society USA and British HIV Association 2008 guidelines are similar, recommending therapy at a CD4 less than 350 cells $/ \mu \mathrm{L}$ and consideration of therapy at higher CD4 counts $[54,55]$. In November 2009, the WHO raised its recommended CD4 threshold for treatment to 350 cells $/ \mu \mathrm{L}$, a shift that will undoubtedly have profound policy consequences throughout the developing world [27••]. They recommended deferral of therapy for all patients with CD4 more than 350 cells $/ \mu \mathrm{L}$.

\section{Key Clinical Studies Still in Progress}

Two clinical trials are currently in progress, the results of which are eagerly anticipated by the HIV community. START (Strategic Timing of Antiretroviral Therapy) is a clinical trial enrolling patients with CD4 counts more than 500 cells $/ \mu \mathrm{L}$ and randomizing them to either immediate therapy or deferral of therapy until the CD4 count is less than 350 cells $/ \mu \mathrm{L}$. It will examine both AIDS-related and non-AIDS-related events and deaths. HIV Prevention Trials Network (HPTN) 052 is a clinical trial examining strategies for preventing transmission of HIV in the developing world. It is enrolling serodiscordant couples in which the HIV-positive patient has a CD4 count of 350 to 550 cells $/ \mu \mathrm{L}$, and randomizing these HIV-positive index patients to either immediate therapy or deferral of therapy until a CD4 less than 


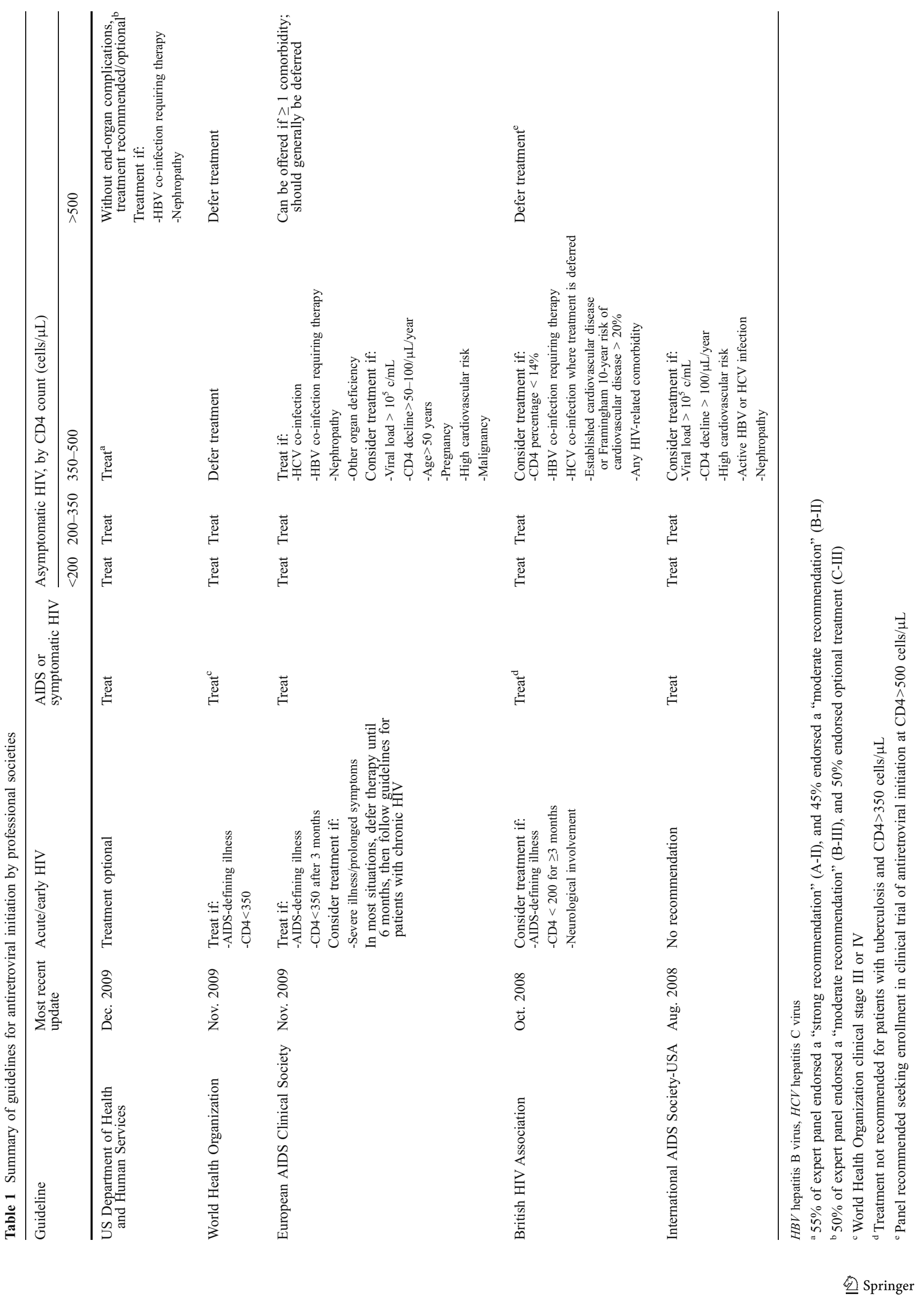


250 cells $/ \mu \mathrm{L}$. While the primary outcome is HIV transmission to the HIV-negative partner, a secondary outcome will be the clinical course of the index patients starting therapy at different CD4 counts. Building on the CIPRA-HT001 study, HPTN 052 will likely provide valuable insights into the benefits and risks of initiating antiretroviral therapy at higher CD4 counts in a developing-world setting.

\section{Conclusions}

Although the debate regarding when to start antiretroviral therapy has been present for over two decades, consensus on this question has been hard to achieve. This lack of clarity continues in the current era, with major guidelines recommending very different treatment strategies. All agree, however, that the pendulum has swung back in favor of more aggressive approaches to therapy. The philosophy of delaying potentially toxic medications as long as possible has increasingly shifted toward a philosophy of initiating therapy as soon as possible. The debate now and in the future will likely focus on the role of antiretroviral therapy in preventing versus causing nonAIDS-related conditions. These include heart, bone, liver, kidney, and neurocognitive disease, as well as non-AIDS malignancies, all of which appear to be more common in HIVpositive persons compared to their age-matched uninfected peers. The potential public health benefits of early therapy in reducing HIV transmission are generating thoughtful discussion contributing to this debate. Several clinical trials of different therapeutic strategies that are still in progress promise to shed valuable light in the coming years on the critical question of when to start antiretroviral therapy.

Disclosure Dr. Deeks has received research support from Pfizer, Merck, Bristol-Myers Squibb, and Gilead, and has done ad hoc consulting for GlaxoSmithKline. Dr. Jain reports no potential conflict of interest relevant to this article.

Open Access This article is distributed under the terms of the Creative Commons Attribution Noncommercial License which permits any noncommercial use, distribution, and reproduction in any medium, provided the original author(s) and source are credited.

\section{References}

Papers of particular interest, published recently, have been highlighted as:

•- Of major importance

1. Wilkin TJ, Gulick RM: When to start antiretroviral therapy? Clin Infect Dis 2008, 47:1580-1586.
2. Volberding PA, Lagakos SW, Koch MA, et al.: Zidovudine in asymptomatic human immunodeficiency virus infection. A controlled trial in persons with fewer than 500 CD4-positive cells per cubic millimeter. The AIDS Clinical Trials Group of the National Institute of Allergy and Infectious Diseases. N Engl J Med 1990, 322:941-949.

3. Concorde: MRC/ANRS randomised double-blind controlled trial of immediate and deferred zidovudine in symptom-free HIV infection. Concorde Coordinating Committee. Lancet 1994, 343:871-881.

4. Volberding PA, Lagakos SW, Grimes JM, et al.: A comparison of immediate with deferred zidovudine therapy for asymptomatic HIV-infected adults with CD4 cell counts of 500 or more per cubic millimeter. AIDS Clinical Trials Group. N Engl J Med 1995, 333:401-407.

5. Ho DD: Time to hit HIV, early and hard. N Engl J Med 1995, 333:450-451.

6. Panel on Antiretroviral Guidelines for Adults and Adolescents: Guidelines for the use of antiretroviral agents in HIV-1-infected adults and adolescents. Department of Health and Human Services, April 24, 1998: 1-91. Available at: http://aidsinfo.nih. gov/ContentFiles/AdultandAdolescentGL04241998014.pdf. Accessed January 25, 2010.

7. Panel on Antiretroviral Guidelines for Adults and Adolescents: Guidelines for the use of antiretroviral agents in HIV-1-infected adults and adolescents. Department of Health and Human Services, January 28, 2000: 1-100. Available at: http://aidsinfo. nih.gov/ContentFiles/AdultandAdolescentGL01282000010.pdf. Accessed January 25, 2010.

8. Egger M, May M, Chene G, et al.: Prognosis of HIV-1-infected patients starting highly active antiretroviral therapy: a collaborative analysis of prospective studies. Lancet 2002, 360:119-129.

9. Hogg RS, Yip B, Chan KJ, et al.: Rates of disease progression by baseline CD4 cell count and viral load after initiating triple-drug therapy. JAMA 2001, 286:2568-2577.

10. Palella FJ Jr, Deloria-Knoll M, Chmiel JS, et al.: Survival benefit of initiating antiretroviral therapy in HIV-infected persons in different CD4+ cell strata. Ann Intern Med 2003, 138:620-626.

11. Panel on Antiretroviral Guidelines for Adults and Adolescents: Guidelines for the use of antiretroviral agents in HIV-1-infected adults and adolescents. Department of Health and Human Services, February 5, 2001: 1-112. Available at: http://aidsinfo. nih.gov/ContentFiles/AdultandAdolescentGL02052001009.pdf. Accessed January 25, 2010.

12. • El-Sadr WM, Lundgren JD, Neaton JD, et al.: CD4+ countguided interruption of antiretroviral treatment. N Engl J Med 2006, 355:2283-2296. This landmark randomized controlled trial showed that continuous antiretroviral therapy, compared with therapy interrupted around CD4 counts of 250 to 350 cells $\mu \mathrm{L}$, was associated with lower mortality and morbidity. This was the first study to highlight the role of untreated HIV infection in nonAIDS morbidity and mortality.

13. •• Emery S, Neuhaus JA, Phillips AN, et al.: Major clinical outcomes in antiretroviral therapy (ART)-naive participants and in those not receiving ART at baseline in the SMART study. J Infect Dis 2008, 197:1133-1144. This post hoc analysis of untreated patients in the SMART study in essence was a randomized study of early versus deferred therapy. It provides some support for starting therapy in patients with CD4 counts more than 350 cells/ $\mu \mathrm{L}$.

14. Kaplan JE, Hanson DL, Cohn DL, et al.: When to begin highly active antiretroviral therapy? Evidence supporting initiation of therapy at CD4+ lymphocyte counts $<350$ cells/microL. Clin Infect Dis 2003, 37:951-958.

15. Jaen A, Esteve A, Miro JM, et al.: Determinants of HIV progression and assessment of the optimal time to initiate highly active antiretroviral therapy: PISCIS Cohort (Spain). J Acquir Immune Defic Syndr 2008, 47:212-220. 
16. •- Kitahata MM, Gange SJ, Abraham AG, et al.: Effect of early versus deferred antiretroviral therapy for HIV on survival. N Engl J Med 2009, 360:1815-1826. This highly influential cohort study showed mortality benefits in patients who initiated antiretroviral therapy at CD4 counts more than 500 cells/ $\mu \mathrm{L}$ compared to less than 500 cells $/ \mu L$.

17. Gelinck LB, van der Ende ME: Early versus deferred antiretroviral therapy for HIV. N Engl J Med 2009, 361:823; author reply 823-824.

18. Buchbinder SP, Jain V: Early versus deferred antiretroviral therapy for HIV. N Engl J Med 2009, 361:822; author reply 823-824.

19. • Sterne JA, May M, Costagliola D, et al.: Timing of initiation of antiretroviral therapy in AIDS-free HIV-1-infected patients: a collaborative analysis of 18 HIV cohort studies. Lancet 2009, 373:1352-1363. This very important large cohort analysis showed benefits of antiretroviral initiation at a CD4 threshold of 350 cells/ $\mu L$, but no benefit to initiation of therapy at higher CD4 counts.

20. Phillips AN, Lepri AC, Lampe F, et al.: When should antiretroviral therapy be started for HIV infection? Interpreting the evidence from observational studies. AIDS 2003, 17:1863-1869.

21. Wood R, Lawn SD: Should the CD4 threshold for starting ART be raised? Lancet 2009, 373:1314-1316.

22. Hammer SM, Squires KE, Hughes MD, et al.: A controlled trial of two nucleoside analogues plus indinavir in persons with human immunodeficiency virus infection and CD4 cell counts of 200 per cubic millimeter or less. AIDS Clinical Trials Group 320 Study Team. N Engl J Med 1997, 337:725-733.

23. Zolopa A, Andersen J, Powderly W, et al.: Early antiretroviral therapy reduces AIDS progression/death in individuals with acute opportunistic infections: a multicenter randomized strategy trial. PLoS One 2009, 4:e5575.

24. Violari A, Cotton MF, Gibb DM, et al.: Early antiretroviral therapy and mortality among HIV-infected infants. N Engl J Med 2008, 359:2233-2244.

25. World Health Organization: Antiretroviral therapy for HIV infection in adults and adolescents: recommendations for a public health approach. 2006: 1-134. Available at: http://www.who.int/ hiv/pub/guidelines/artadultguidelines.pdf. Accessed January 25, 2010.

26. • Severe P, Pape J, Fitzgerald D: A randomized clinical trial of early versus standard antiretroviral therapy for HIV-Infected patients with a CD4 T cell count of 200-350 cells/ml (CIPRAHT001) [abstract 1230c]. Presented at the 49th Interscience Conference on Antimicrobial Agents and Chemotherapy (ICAAC). San Francisco, CA; September 12-15, 2009. This was the first randomized controlled trial in a developing-world setting to show clinical benefits of initiating antiretroviral therapy at CD4 cell counts of 200 to 350 cells/ $\mu L$ compared to less than 200 cells $/ \mu L$.

27. . World Health Organization: Antiretroviral therapy for HIV infection in adults and adolescents. November 30, 2009: 1-28. Available at: http://www.who.int/hiv/pub/arv/rapid advice art. pdf. Accessed January 25, 2010. These recently updated $\bar{W} H O$ guidelines recommend therapy for all patients with CD4 cell counts less than 350 cells $/ \mu L$.

28. - ATCC: Life expectancy of individuals on combination antiretroviral therapy in high-income countries: a collaborative analysis of 14 cohort studies. Lancet 2008, 372:293-299. This large cohort analysis showed that despite tremendous recent gains in life expectancy among treated HIV-positive persons, their mortality remains elevated compared to HIV-negative persons.

29. Lohse N, Hansen AB, Pedersen G, et al.: Survival of persons with and without HIV infection in Denmark, 1995-2005. Ann Intern Med 2007, 146:87-95.

30. Bhaskaran K, Hamouda O, Sannes M, et al.: Changes in the risk of death after HIV seroconversion compared with mortality in the general population. JAMA 2008, 300:51-59.
31. Harrison KM, Song R, Zhang X: Life expectancy after HIV diagnosis based on national HIV surveillance data from 25 states, United States. J Acquir Immune Defic Syndr 2010, 53:124-130.

32. Cockerham L, Scherzer R, Zolopa A, et al.: Association of HIV infection, demographic and cardiovascular risk factors with allcause mortality in the recent HAART era. J Acquir Immune Defic Syndr 2010, 53:102-106.

33. Deeks SG, Phillips AN: HIV infection, antiretroviral treatment, ageing, and non-AIDS related morbidity. BMJ 2009, 338:a3172.

34. Phillips AN, Neaton J, Lundgren JD: The role of HIV in serious diseases other than AIDS. AIDS 2008, 22:2409-2418.

35. Sackoff JE, Hanna DB, Pfeiffer MR, Torian LV: Causes of death among persons with AIDS in the era of highly active antiretroviral therapy: New York City. Ann Intern Med 2006, 145:397-406.

36. Baker JV, Peng G, Rapkin J, et al.: CD4+ count and risk of nonAIDS diseases following initial treatment for HIV infection. AIDS 2008, 22:841-848.

37. Weber R, Sabin CA, Friis-Moller N, et al.: Liver-related deaths in persons infected with the human immunodeficiency virus: the $\mathrm{D}$ : A:D study. Arch Intern Med 2006, 166:1632-1641.

38. Monforte A, Abrams D, Pradier C, et al.: HIV-induced immunodeficiency and mortality from AIDS-defining and non-AIDSdefining malignancies. AIDS 2008, 22:2143-2153.

39. Abrams D, Levy Y, Losso MH, et al.: Interleukin-2 therapy in patients with HIV infection. N Engl J Med 2009, 361:1548-1559.

40. Kelley CF, Kitchen CM, Hunt PW, et al.: Incomplete peripheral $\mathrm{CD} 4+$ cell count restoration in HIV-infected patients receiving long-term antiretroviral treatment. Clin Infect Dis 2009, 48:787794.

41. Valdez H, Smith KY, Landay A, et al.: Response to immunization with recall and neoantigens after prolonged administration of an HIV-1 protease inhibitor-containing regimen. ACTG 375 team. AIDS Clinical Trials Group. AIDS 2000, 14:11-21.

42. Deeks SG, Kitchen CM, Liu L, et al.: Immune activation set point during early HIV infection predicts subsequent CD4+ T-cell changes independent of viral load. Blood 2004, 104:942-947.

43. Giorgi JV, Hultin LE, McKeating JA, et al.: Shorter survival in advanced human immunodeficiency virus type 1 infection is more closely associated with $\mathrm{T}$ lymphocyte activation than with plasma virus burden or virus chemokine coreceptor usage. J Infect Dis 1999, 179:859-870.

44. Liu Z, Cumberland WG, Hultin LE, et al.: CD8+ T-lymphocyte activation in HIV-1 disease reflects an aspect of pathogenesis distinct from viral burden and immunodeficiency. J Acquir Immune Defic Syndr Hum Retrovirol 1998, 18:332-340.

45. •- Kuller LH, Tracy R, Belloso W, et al.: Inflammatory and coagulation biomarkers and mortality in patients with HIV infection. PLoS Med 2008, 5:e203. This study demonstrated that biomarkers of systemic inflammation and hypercoagulability are elevated in patients with untreated HIV infection; these markers were independently associated with morbidity and mortality in both untreated and treated infection.

46. Hsue PY, Hunt PW, Schnell A, et al.: Role of viral replication, antiretroviral therapy, and immunodeficiency in HIV-associated atherosclerosis. AIDS 2009, 23:1059-1067.

47. Hunt PW, Martin JN, Sinclair E, et al.: T cell activation is associated with lower CD4+ T cell gains in human immunodeficiency virus-infected patients with sustained viral suppression during antiretroviral therapy. J Infect Dis 2003, 187:1534-1543.

48. Robbins GK, Spritzler JG, Chan ES, et al.: Incomplete reconstitution of $\mathrm{T}$ cell subsets on combination antiretroviral therapy in the AIDS Clinical Trials Group protocol 384. Clin Infect Dis 2009, 48:350-361.

49. Blower SM, Gershengorn HB, Grant RM: A tale of two futures: HIV and antiretroviral therapy in San Francisco. Science 2000, 287:650-654. 
50. Velasco-Hernandez JX, Gershengorn HB, Blower SM: Could widespread use of combination antiretroviral therapy eradicate HIV epidemics? Lancet Infect Dis 2002, 2:487-493.

51. • Granich RM, Gilks CF, Dye C, et al.: Universal voluntary HIV testing with immediate antiretroviral therapy as a strategy for elimination of HIV transmission: a mathematical model. Lancet 2009, 373:48-57. This mathematical modeling study of the "test and treat" approach (universal HIV testing followed by treatment of all HIV-positive persons older than 15 years at any CD4 count) showed that eradication of the HIV epidemic is theoretically possible.

52. • Panel on Antiretroviral Guidelines for Adults and Adolescents: Guidelines for the use of antiretroviral agents in HIV-1-infected adults and adolescents. Department of Health and Human Services, December 1, 2009:1-161. Available at: http://aidsinfo.
nih.gov/contentfiles/AdultandAdolescentGL.pdf. Accessed January 25,2010 . These recently updated DHHS guidelines recommend therapy for all patients with CD4 cell counts less than 500 cells $/ \mu L$.

53. European AIDS Clinical Society (EACS): Guidelines: clinical management and treatment of HIV-infected adults in Europe, version 5. November, 2009:1-80. Available at: http://european aidsclinicalsociety.org/guidelinespdf/1_Treatment_of_HIV_Infec ted_Adults.pdf. Accessed January 25, 2010.

54. Gazzard BG, Anderson J, Babiker A, et al.: British HIV Association Guidelines for the treatment of HIV-1-infected adults with antiretroviral therapy 2008. HIV Med 2008, 9:563-608.

55. Hammer SM, Eron JJ Jr, Reiss P, et al.: Antiretroviral treatment of adult HIV infection: 2008 recommendations of the International AIDS Society-USA panel. JAMA 2008, 300:555-570. 